IZA DP No. 5616

Unofficial Development Assistance:

A Dynamic Model of Charities' Donation Income

Wiji Arulampalam

Peter G. Backus

John Micklewright

April 2011 


\title{
Unofficial Development Assistance: A Dynamic Model of Charities' Donation Income
}

\author{
Wiji Arulampalam \\ University of Warwick \\ and IZA \\ Peter G. Backus \\ University of Warwick \\ John Micklewright \\ IOE, University of London \\ and IZA
}

\author{
Discussion Paper No. 5616 \\ April 2011 \\ IZA \\ P.O. Box 7240 \\ 53072 Bonn \\ Germany \\ Phone: +49-228-3894-0 \\ Fax: +49-228-3894-180 \\ E-mail: iza@iza.org
}

Any opinions expressed here are those of the author(s) and not those of IZA. Research published in this series may include views on policy, but the institute itself takes no institutional policy positions.

The Institute for the Study of Labor (IZA) in Bonn is a local and virtual international research center and a place of communication between science, politics and business. IZA is an independent nonprofit organization supported by Deutsche Post Foundation. The center is associated with the University of Bonn and offers a stimulating research environment through its international network, workshops and conferences, data service, project support, research visits and doctoral program. IZA engages in (i) original and internationally competitive research in all fields of labor economics, (ii) development of policy concepts, and (iii) dissemination of research results and concepts to the interested public.

IZA Discussion Papers often represent preliminary work and are circulated to encourage discussion. Citation of such a paper should account for its provisional character. A revised version may be available directly from the author. 


\section{ABSTRACT}

\section{Unofficial Development Assistance: A Dynamic Model of Charities' Donation Income*}

The empirical literature on the determinants of charities donation income, distinguishing the charitable cause, is small. We extend the literature in several ways. First, we focus on overseas development charities allowing us to give more consideration to the particular characteristics of this cause. Second, we look at the impact of macroeconomic change over a quarter century including changes in household income and in government spending on ODA, as well as 'charity level' variables that earlier authors have considered. Third, we use a general dynamic model and rigorous testing procedures to arrive at our specification. Using a newly assembled long panel of data, we find evidence of a strong, but diminishing fundraising effect. We find no evidence of crowding out by either grants made directly to charities or by changes in the public provision of development funding.

JEL Classification: L3, D1, D6, F3

Keywords: charitable giving, overseas development

Corresponding author:

Peter G. Backus

Department of Economics

University of Warwick

Coventry CV4 7AL

United Kingdom

E-mail: p.g.backus@warwick.ac.uk

\footnotetext{
* This research was supported by ESRC project grant 'Giving to Development' (RES-155-25-0061), which formed part of the Non-Governmental Public Action programme. The project was conducted in conjunction with Tony Atkinson, Cathy Pharoah and Sylke Schnepf and we thank them for very helpful discussion and suggestions; we draw on our joint work developing the panel database reported on Atkinson et al. (2008), but errors of commission or omission in the current paper are ours alone. We are most grateful to the Charities Aid Foundation for allowing access to their data; data from Charity Trends from 2001 onwards are used also with permission of Waterlow Ltd who retain the copyright in them. We thank lan Mocroft for much help in documenting government funding of development charities. Many thanks to Robin Naylor for comments and suggestions.
} 


\section{Introduction}

Rich countries are important donors of development finance to poorer countries. Attention often focuses on Official Development Assistance (ODA), given by governments in the form of bilateral or multilateral aid. However, contributions from private individuals are also prominent. These include remittances from migrants, which surpass ODA in importance and that have been the subject of considerable study (e.g. see Solimano 2005). But they also include donations made to charities working abroad for overseas aid and humanitarian assistance. These private charitable donations for overseas development have received much less attention from researchers. The large theoretical and empirical literatures on charitable giving tend not to distinguish giving by cause (e.g. see the survey in Andreoni (2006)). In this paper, we model donations received by overseas development charities in one rich country, the UK. In 2004-5, giving in this form was equal to about a quarter of the figure for the UK's ODA, a not inconsiderable amount.

We use a newly constructed panel on individual charity finances that spans over 25 years. Our focus on giving for overseas development rather than total giving allows us to pay more attention to the particular characteristics of giving to this cause. Our empirical modelling draws in part on the theoretical model proposed by Atkinson (2009), who explicitly considers the giving to overseas development charities by private individuals. Our work extends the existing empirical literature that has focused on charity level factors, such as fundraising and government grants received by charities. As well as these influences we consider three important aspects of the changing external environment within which overseas development charities have operated over the quarter century that is our focus.

First, we analyse the impact of ODA on private giving for development. Such public provision of a public good may crowd out private provision but it is a possibility that has seen little or no attention. The crowding-out hypothesis has typically been studied with respect to changes in the provision of public grants to individual charities. However, as made clear by the models developed in Duncan (2004) and, for the specific case of 
overseas development, Atkinson (2009), an increase in public provision of the public good may have a similar crowding-out effect by increasing the welfare of the end-recipients of the charity's work. ODA represents public provision of this sort.

Second, we consider the impact of changes in the macroeconomic environment in which donations are made. In particular, the substantial changes in household income over the period that we consider allow us to estimate the income elasticity of giving for overseas development. Although the existing empirical literature on charitable giving contains many estimates of income elasticities there are relatively few of giving by cause. ${ }^{1}$ The 2008-9 recession has highlighted interest in the impact of the economic cycle on private giving, including the specific giving for overseas development (House of Commons 2009).

Third, we estimate the impact of major disasters on donations - a key feature in giving to international charities - of which the Ethiopian famine of the early 1980s and the Asian Tsunami 20 years later are the most prominent examples. In the case of the Ethiopian famine we investigate a continuing impact on overseas giving in addition to the short-run impact.

Section 2 outlines our framework for modelling giving for overseas development, drawing on the existing literature. Section 3 describes our panel data on individual charity finances, which are assembled from the annual publication Charity Trends of the Charities Aid Foundation (CAF). The same source was drawn on by Khanna, Posnett and Sandler (1995) and Khanna and Sandler (2000). However, these authors did not consider the impact of changes in the external environment on charitable donations as their data covered only eight years, in contrast to the 27 years included in our panel. The impact of ODA, household incomes, and disasters do not feature in their analysis. Nor did their work have any particular focus on the determinants of overseas giving, much of which focuses on giving to all causes taken together (although 'overseas' is one of four sub-sectors that they use in some of their modelling).

\footnotetext{
${ }^{1}$ These use survey microdata on households (e.g. Micklewright and Schnepf 2009) rather than data on the total donations received by individual charities, as we use in this paper.
} 
Section 4 explains our econometric specification. We introduce GMM estimation to the literature on modelling charities' incomes. This allows us to address adequately the issues of endogeneity that pervade empirical modelling of charities' donations, as noted by earlier authors. It also permits our model to have a dynamic specification, which we argue to be appropriate, in contrast to the static specifications used by earlier authors. Section 5 presents our results and Section 6 concludes.

\section{Modelling charitable giving for development}

Charities receive income from a number of sources such as the sale of goods and services, grants and voluntary contributions in the form of money donations. Much of the literature on giving has focused on modelling donations as a function of donor characteristics such as income using household or individual level data (see Peloza and Steel (2005) for a survey). Other studies (e.g. Khanna and Sandler (2000) and Tinkleman (2004)) have sought to model donation receipts as a function of charity characteristics such as fundraising expenditure. Donation expenditure of households and the donation receipts of charities are simply two sides of the same coin and are a function of both donor and charity characteristics. Andreoni (2006) in his survey of the literature emphasises that 'the interaction between supply and demand for philanthropy has been largely neglected in both theoretical and empirical analysis'. Our empirical model contains elements suggested from work on both sides of the market, integrating both aggregate donor and individual charity characteristics into a single framework.

On the supply side, there is a rich body of theory based on public goods and 'warmglow' motives. Models have not usually focused on any particular charitable cause. In this sense, giving has tended to be treated as a homogeneous good; however people are often not indifferent as to where their donation ends up - they deliberately give to a specific cause. Atkinson (2009) argues that the public goods and warm-glow models fail to capture key aspects of giving to international development charities, including donor motivation and the ways that charities set about fundraising. He proposes a new 'identification' 
model that incorporates elements of both the existing approaches.

In Atkinson's model, individuals giving money to a development charity 'identify' with the ultimate recipients on a one-to- $m$ basis, where $m$ is a small number, e.g. the marginal poor family or village to which the charity can extend help with the individual's donation - reflected in how charities often promote their work when seeking funds. The $m$ recipients' wellbeing enters the donor's utility function - giving for development is not merely motivated by warm glow. In contrast to the public goods model, however, donor utility is not affected by the well-being of all recipients. This is similar to the 'impact giving' model of Duncan (2004), although Duncan had no specific charitable cause in mind. So the standard problem of the public goods model - free riding on others' donations - does not arise. The 'identification' model can therefore explain why people do contribute to large development charities.

Government ODA, our first focus, features prominently in the model: unlike other people's donations, ODA is assumed to influence the living standards of the recipients with whom the donor identifies. This provides a possible source of crowding-out. The same effect would occur within Duncan's impact giving model - public provision of the public good reduces need and hence donor motivation. In this case, increases in ODA lead to lower donations. ${ }^{2}$ In view of the scale of ODA in relation to private donations, underlined in the Introduction, it seems essential to take this possibility into account when modelling empirically development charities' donation income. On the other hand, 'crowding in' of private donations can be expected if increases in ODA raise donors' or potential donors' perceptions of need by drawing attention to problems of developing countries. An increase in ODA may act as a signal. For example, the UK government's prominent commitment in the late 1990s to increase ODA and its recent pledge to sustain ODA levels might be seen in this light. Finally, some donors may of course be unaware of ODA levels or changes.

\footnotetext{
${ }^{2}$ However, Atkinson (2009) notes that in practice ODA and private donations may not be perfect substitutes. They may fund different activities. Were these to be complementary, ODA would crowd in private donations. He offers the example of ODA funding school construction while private donations fund the textbooks.
} 
Household income, our second focus, is emphasised in the warm glow approach and again features in the identification model. The quarter-century covered by our panel of charities saw a 2.5 fold increase in real after-tax household incomes in the UK. In other work with UK survey data on individuals, the authors find little evidence that the income elasticity of donations to international development differs much from that for 'domestic' causes, taken together (Micklewright and Schnepf 2009). In the present paper we exploit variation in incomes over time rather than across individuals to add to what is only a small existing pool of evidence on how the impact of income on charitable giving varies by cause. Income growth was far from steady across the period we consider and our panel covers the recessions of the early 1980s and early 1990s. We also allow for changes in the distribution of income. The rise in income in the UK was accompanied by a change in its distribution. Over the period as a whole, inequality of incomes rose substantially. If those on higher incomes have a higher marginal propensity to give we would expect this to have led to an increase in donations. Glazer and Konrad (1996) present a signalling model of charitable giving that predicts an increase in giving arising from an increase in inequality.

An empirical model of charitable donations that focuses on international development charities needs to recognise emergency relief as an important influence on giving, a third novel feature of our analysis. A major humanitarian crisis can have an immediate and large impact on the donors' perceptions of need that are at the heart of the identification model. The period which we consider includes the Ethiopian famine in 1984-85 and the Asian Tsunami of Christmas 2004. Both of these disasters saw huge responses from private donors. In the case of the Ethiopian famine, we explore the possibility of persistent long-term effects on giving which have not been considered in the literature to date.

Besides allowing for these three influences on donations, we follow existing practise by considering the impact of fundraising, government grants, and other autonomous incomes (e.g. bequests), drawing on the (smaller) literature that focuses on the demand side. The importance of fundraising is underlined by Andreoni (2006): 'fund-raisers know that to get money donated, you have to ask for it', and asking for money, including promotion 
of a charity's work in the eyes of potential donors, costs money. Within Atkinson's identification model, fundraising campaigns help increase the awareness of recipients' need. Fundraising therefore has a direct positive impact on donations. But, following RoseAckerman (1982) and Weisbrod and Dominguez (1986), fundraising is assumed also to affect the 'price' of donations, which is a measure of the cost to a donor of increasing the charitable output of a charity by $£ 1$. This is generally specified as $(1-t) /(1-f-a)$ where $t$ is marginal rate of tax faced by the individual and $f$ and $a$ are the proportions of total expenditure spent by the charity on fundraising and administration respectively. Fundraising and administration are seen in the literature in this context of price as leakages, increasing the price of giving and hence hypothesised to reduce giving. As Atkinson points out, the threat of leakage features prominently in debate about overseas aid. It is, however, typically the leakage that is perceived to takes place through corruption and misgovernment in the recipient country. ${ }^{3}$ The price variable captures none of this loss of funds (unless one can argue that the loss is reflected in higher administration costs resulting from charities' attempts to deal with the problem). However, we include the price variable so as to aid comparability with the earlier literature.

Fundraising and administrative expenditure may also have a second negative effect on donations if a charity's reputation is affected by what donors perceive to be an excessive level of fundraising, as opposed to a share in total expenditure. A large fundraising drive increases the price faced by donors in the sense just defined but may have a secondary negative impact on donors' desire to contribute to that particular charity if the observed level of advertising, e.g. direct mailings, is perceived as excessive. This effect may be different from donor response to leakage, as captured by the price. The price captures the changes in the size of the donation required to increase the welfare of the end-beneficiary by some desired amount. Such a price will be greater than one for any positive level of fundraising or administrative expenditure and captures the relative level of non-charitable expenditures, whereas the excessive fundraising effect is caused by absolute excess non-

\footnotetext{
${ }^{3}$ For example, see the qualitative research reported in Atkinson and Eastwood (2007), carried out as part of our ESRC-funded project.
} 
charitable expenditures. We therefore allow donations to be non-linear in non-charitable expenditures such as fundraising, as well as including the price of giving as in the earlier literature.

Government grants to charities may crowd out their donation income - donors seeing the charity as less needy. Or they may 'crowd in' more giving, being viewed by donors as a signal that a charity is worth supporting. There are also arguments for no impact: Horne et al (2005) find that donors, responding to a US survey, have little knowledge of the government grants received by the charities to which they give. ${ }^{4}$ In the case of the UK overseas development charities, these grants represented a total of about $£ 250 \mathrm{~m}$ in 2004-5, compared to donations of about $£ 1$ bn (Atkinson et al. 2008). Over the period we consider, they grew enormously, by a factor of 10 between the late 1970s and the mid1990s when there was a levelling off. In general, these grants are to fund programme work in developing countries, and therefore they are included in figures for ODA, although they constitute only a small part of the total (about 5 per cent in 2004). We do not hypothesise the sign of any impact, since as noted earlier there are arguments for both crowding out and for crowding in.

We therefore specify our model for the donations received by a development charity as a dynamic model using the following general form:

$$
\text { Donations }=f\left(\begin{array}{l}
\text { ODA } \\
\text { household income } \\
\text { disasters } \\
\text { fundraising } \\
\text { price } \\
\text { government grants } \\
\text { autonomous income } \\
\text { unobserved charity fixed effects }
\end{array}\right\} B
$$

Prior empirical studies using charity level data have been restricted to the Group B variables. Group A are variables that our long panel allow us to consider in addition. We also allow for unobserved charity level effects (sometimes allowed for in the existing

\footnotetext{
${ }^{4}$ Andreoni and Payne (2003) argue that crowding out by grants may occur on the demand side, by reducing fundraising, as well as on the supply side.
} 
literature, depending on whether panel data were used), which may be correlated with observed variables. This could include a charity's long-term reputation, for example. Finally, in another major departure from previous practice, we allow for a general dynamic model and use rigorous testing procedures to arrive at a parsimonious specification although only the lagged value of donations is significant among the lagged variables in the chosen specification. There are good institutional reasons for such a dynamic specification. For example, many individuals make donations through bank standing orders, which they fail to adjust each year as their circumstances change. Consider the example of a charity that hires fundraisers to sign up new donors among high street shoppers (charity 'chuggers' as they have become known in the UK). New donors sign up to give indefinitely and the charity's fundraising expenditure in that year produces a continued stream of income. The dynamic model we use allows us to separate out the persistence found in the donations data that is due to an unobserved charity-specific effect from that due to the effect coming via lagged donations. The model also allows us to separate the long-run effects from the short-run ones.

The existing literature has led to varied conclusions about the impact of the Group B variables. The two UK papers that have used much shorter panels constructed from the CAF data to estimate static models, Khanna et al. (1995) and Khanna and Sandler (2000) both found no impact of government grants on giving to overseas charities and a positive impact of fundraising, but sharply differing impacts of the price variable. Khanna et al. (1995) addressed the potential endogeneity of the Group B variables with what they admit is the 'quick fix' (p.1547) of replacing current values with the one period lags, a practice also adopted by Weisbrod and Dominguez (1986) and Okten and Weisbrod (2000) in models for the US. Khanna and Sandler instrumented government grants but treated other variables as exogenous. In what follows we instrument all potentially endogenous variables within a dynamic model, the dynamic specification allowing for the identification of both long-run and short-run impacts unlike in the earlier literature. 


\section{Data and variable definitions}

Our data come from the Charity Trends reports published by the Charities Aid Foundation (CAF) from 1978 to 2006 , covering donations to $2004 .^{5}$ The reports document the donations, bequests, other incomes, e.g. government grants and selected expenditures of the leading fundraising charities in the UK. The figures for donations for each charity are obtained by subtracting the figure for legacies from the total given for "voluntary income', the variable on which the CAF rankings are based. CAF first included the top 200 fundraising charities. Coverage increased to the top 300 in 1985 and top 400 in 1986, and finally the top 500 from 1991. The great bulk of donations come from individuals; a small part comes from the corporate sector and grant-making charitable trusts but these donations cannot be separated in the data. Full details of the data and how we cleaned and then assembled them into a panel are given in Atkinson et al. (2008).

We define as 'development' charities both the charities grouped under this heading in the CAF reports and the 'religious international' charities that are separately identified by CAF. ${ }^{6}$ The dataset contains a total of 70 overseas development charities that appear in Charity Trends at least once during the period we analyse, of which we drop two, for reasons explained below, leaving us with 68 . We lose a further 10 charities ( 21 observations in total) as there must be at least three observations for the estimation method we use (discussed in detail below). The names of the remaining 58 charities are listed in Appendix A, together with, in each case, the year of entry to the dataset and the number of annual observations for the charity. The panel has gaps meaning the number of observations is not always the same as the exit year minus the entry year plus 1 . These gaps appear for a number of reasons including changing accounting years, duplicate data used by CAF from one year to the next and unavailable CAF reports (see Atkinson et al. 2008). The charities all have a principal focus on overseas development and relief, but include a

\footnotetext{
5 The last CAF report in this series was published in 2007, but a change in definition means that the information for donations in that year is not consistent with that in earlier years. There was no report in 1995, and we did not have access to the report for 1981.

${ }^{6}$ We exclude the Priory of St John, commonly known as St John Ambulance, which is included by $\mathrm{CAF}$ in the first group. We do not include missionary charities.
} 
number that serve domestic as well as overseas causes e.g. the Red Cross and Save the Children. The median year of entry is 1989 and the median number of observations is 12 years.

There was a striking rise in the real value of donations across the quarter-century that we consider, with an average annual growth rate for overseas charities among the top 200 fundraisers of nearly 7.5 per cent, a little above that for charities as a whole (see Atkinson et al. 2008 for details). This growth far outstripped the 2 per cent average annual growth in real after-tax household income. It was also far larger than the rise in the UK government's ODA, which grew in real terms by a factor of just 1.5 over the period, with a decline in the early 1980s and stagnation until the late 1990s when renewed growth followed a commitment to reach the UN target of 0.7 per cent of GDP.

The years 1984-85 saw a spike in overseas donations on account of the response to the Ethiopian famine. This was in part stimulated by Bob Geldof, who organised the Band Aid Christmas single in 1984 and the Live Aid concerts in 1985. Geldof's Band Aid Trust was the charity with the most donations in the UK in 1985 - among all causes and not just overseas development - with $£ 122 \mathrm{~m}$ (in 2007 prices). We exclude this charity from our analysis since it was not founded to engage in annual fundraising. Its removal still leaves a spike in the two years. For example, Oxfam had a record year in 1984, with its $£ 109 m$ of donations (in 2007 prices) nearly double the level of the year before. We also exclude Comic Relief which raises funds with a telethon and associated events every two years, so it does not raise funds each year like other charities.

Table 1 gives summary statistics for the variables entered in our model. Besides total after-tax income, we include a measure of income inequality that focuses on the top half of the distribution, the ratio of the 90th to the 50th percentile of equivalised household net income. ${ }^{7}$ We experiment with two measures of ODA. The first is in levels and is net of government grants to overseas development charities, which are included in ODA, as explained earlier. The second measure is total ODA. We experiment with this alternative

\footnotetext{
7 The variable is taken from http://www.ifs.org.uk/fiscalFacts and refers to equivalised after-tax (before housing costs) household income.
} 
measure on the grounds that donors or potential donors may be more aware of this way of describing the extent of the UK government's provision since it is the way that ODA is often presented in the mass media.

\section{[Table 1 about here]}

The main body of Table 1 reports on the charity level variables. The unit of analysis is the charity-year. Mean annual donations received by development charities is $£ 11.5 \mathrm{~m}$ (2007 prices). Information on fundraising is missing or is recorded as zero in 10 percent of cases. The percentages of zeros or missing data are substantially higher for government grants - 39 percent and 60 percent respectively. In the case of fundraising, the absence of positive values is not easy to understand - these are all charities that are among the top 500 in terms of donated income and it does not seem likely that this status can be attained without spending money on raising funds. It seems more likely that fundraising expenditure has been absorbed into administration costs, which we identify separately in the table. Average fundraising costs are about 20 percent of donations. Note that charities have other forms of income, legacies and investment income - their sum is entered in the table as 'autonomous' income. So the message is not that charities are spending on average a fifth to a quarter of their total income on fundraising. In the case of government grants, zeros or missing values are easy to understand - many charities do not get government grants. Note that the mean value of the grants, conditional on being positive, is large relative to donations.

As noted in Section 2, the 'price' variable is designed to capture the cost to the donor of increasing a charity’s charitable output by $£ 1$. Following Okten and Weisbrod (2000), and Tinkelman (2004) we assume donors calculate the price of giving using the previous period's expenditure figures due to information lags that are inherent in the distribution of a charity's financial data. We therefore define the period $t$ price as

$$
\text { price }_{i t}=\frac{1}{\left(1-f_{i t-1}-a_{i t-1}\right)}
$$


where $f_{i t-1}$ and $a_{i t-1}$ are the proportion of total expenditure spent on fundraising and administration, respectively, in the previous year. Following the earlier papers using UK data by Posnet and Sandler (1989), Khanna et al (1995) and Khanna and Sandler (2000), we do not include a tax rate when calculating the price variable. Prior to 2000, tax deductions for charitable donations in the UK required giving through one's employer via a payroll deduction or agreeing to covenant income to a charity for several years. ${ }^{8}$ The price variable is calculated only for those observations with positive fundraising and administrative expenditure and represents the average rather than marginal price of increasing the charities output by $£ 1$. Administrative expenditure is sometimes excluded in the calculation of the price variable (Tinkelman 2004) as the purpose of such expenditure is not immediately clear (e.g. managing the charitable output of the charity or managing fundraising staff). The utility of donors can be modelled as a function of the welfare of the final recipients of the charities 'output' or charitable expenditure. The price of increasing this 'output' by one unit therefore accounts for the proportion of the donation that goes to any expense other than the end-recipient, including administrative expenditure, although this may in part be benefiting the end-recipient indirectly.

\section{Model specification and estimation}

After applying rigorous testing procedure to arrive at a parsimonious representation of the data generation process for log donations y, we have the following dynamic $\operatorname{model}^{9}$ :

$$
y_{i t}=\gamma y_{i t-1}+x^{\prime}{ }_{t} \beta+z^{\prime}{ }_{i t} \vartheta+\alpha_{i}+\varepsilon_{i t}
$$

where $i$ and $t$ index charities and years respectively, $y_{i t-1}$ is the one-period lag of

\footnotetext{
${ }^{8}$ Following the same authors, we use the share of total expenditure going to non-charitable expenditures in the construction of the price variable. Weisbrod and Dominguez (1986) and Okten and Weisbrod (2000) use the share of donations going to non-charitable expenditure. Results are not sensitive to the choice of the denominator in equation (2).

${ }^{9}$ We find the log of donations to be more appropriate given the highly skewed distribution of the donations data.
} 
the charity's ( $\log$ ) donations, and $\alpha_{i}$ is included to capture charity-specific unobservables (possibly correlated with the included regressors). The vector $z_{i t}$ contains the Group B charity-specific variables: fundraising expenditure, administrative expenditure, government grants, 'autonomous' income, and the 'price' variable. ${ }^{10}$ In section 2 we argue for a non-linear impact of fundraising and the other variables so we enter them in the model in quadratic form (a log form was tested and rejected by the data). We also include a series of dummy variables to pick up observations with non-positive values for these variables to avoid omitting a significant proportion of observations (we have noted the prevalence of zeroes above.) The effect of these variables on donations is estimated therefore from the positive values only.

The vector $x_{t}$ includes the Group A macroeconomic variables affecting the environment in which donations to overseas development are made: ODA net of government grants, total household income, the 90-50 ratio of household income, and dummy variables to capture the very large disasters that occurred during the observation period, the Ethiopian famine in 1984-85 and the 2004 Boxing Day Tsunami. Since the tsunami disaster took place at the very end of 2004, we define the dummy equal to one for those charities with their financial year ending in the first six months of 2005. All these macro variables are treated as strictly exogenous in all specifications.

There are several econometric issues that need to be addressed in the estimation of equation (3). The first concerns the treatment of the charity specific variables. The contemporaneous values of fundraising, administration and grants may be correlated with the contemporaneous error term $\varepsilon_{i t}$. A positive shock to donations means that a charity can afford to spend more on fundraising. Such a shock could have positive or negative effects on the government grants it receives, depending on how these grants are allocated. ${ }^{11}$ If all such correlations can be captured by the unobserved heterogeneity $\alpha_{i}$, and no lags of donations enter among an explanatory variables, the within-group (WG) estimator would

\footnotetext{
${ }^{10}$ Note that we exclude the age of the organisation, used in some earlier papers, since in the fixedeffects framework we employ the age would simply reduce to an individual time trend.

11 Note the price variable calculated, as we have argued, using the previous period's expenditure figures may be treated as pre-determined, i.e. correlated with past and not current values of the error term $\varepsilon_{i t}$ if $\varepsilon_{i t}$ is not serially correlated.
} 
be consistent. However, in a dynamic model containing a lag of the dependent variable, such as ours, the WG estimator is biased in small samples although the bias goes to zero as $T$ increases (Nickell 1981) as is the case with some charities in our sample.

We experiment with estimation of equation (1) using the WG estimator. This estimator will be inconsistent if there is correlation between the regressors and $\varepsilon_{i t}$, when allowing for the $\alpha_{i}$, as suggested by our discussion of the effects of shocks. A standard approach to the estimation of dynamic panel data models with endogenous regressors is the Generalised Method of Moments (GMM) applied to the first differenced equation (GMM-diff) in order to eliminate the unobserved heterogeneity $\alpha_{i}$ that might be correlated with the regressors. However, as our panel has gaps we use the forward orthogonal deviation (FOD) transformation (Bover and Arellano 1995) to eliminate $\alpha$ i rather than first differencing the data. Instead of subtracting the previous observation from the current, the FOD transformation subtracts the average of all future available observations. ${ }^{12}$ No matter how many gaps, this is computable for all observations except the last in the sample and hence preserves sample sizes in panel data with gaps. ${ }^{13}$ In addition, the transformed error will still be serially uncorrelated if the original equation error term is serially uncorrelated, provided there is no heteroscedasticity in the time dimension (Bover and Arellano 1995). Estimates are obtained using xtabond2 in Stata (Roodman 2009a).

A practical problem with the GMM approach is that the number of instruments, which increases quadratically in $T$, can be numerous. Unlike in two-stage-least-squares (2SLS), where the estimation sample is restricted according to the choice of lags for the instrument, in standard applications of GMM a separate instrument is included for each time period. This approach can produce a large number of instruments which can lead to a finite-sample bias of the GMM estimator.

Roodman (2009b) notes that 'simply by being numerous, instruments can over-fit

\footnotetext{
${ }^{12}$ Forward orthogonal transformation will transforms $y_{i t}$ to $\sqrt{\frac{T_{i t}}{T_{i t}+1}\left(y_{i t}-\frac{1}{T_{i t}} \sum_{s>t} y_{i s}\right)}$. The transformation subtracts the average of the future values from the current value. The weighting equalises the variances in the above transformation.

${ }^{13}$ For example, if a particular $y_{i t}$ is missing, then both $\Delta y_{i t}=y_{i t}-y_{i t-1}$ and $\Delta y_{i t+1}$ will be missing.
} 
instrumented variables, failing to expunge their endogenous components and biasing coefficient estimates toward those from non-instrumenting estimators.' (p. 139) Roodman proposes two methods to deal with the problem of instrument proliferation: (i) collapse the instrument set, and (ii) truncate the instrument set.

Roodman (2009a) suggests collapsing the instrument set to reduce the number of instruments used in GMM (see Appendix B for details). The number of instruments in the collapsed instrument matrix, $Z_{i}$, increases linearly in $T$, rather than quadratically as in the uncollapsed set. However, the number of instruments can still be large and thus collapsing the instrument set may not sufficiently eliminate the finite-sample bias in of the GMM estimator.

We therefore test the sensitivity of our results to truncations of the instrument set, a second method recommended by Roodman (2009b) for limiting instrument proliferation. In practice this means limiting the number of lags of the endogenous regressors used in the instrument set. Alvarez and Arellano (2003) show that the Arellano-Bond estimator is consistent when the lag length of the instrument set is arbitrarily truncated. Alfaro (2008) undertakes a Monte Carlo study of GMM with large $T$ and finds that truncating the instrument set reduces efficiency, creating a trade-off between finite-sample bias and efficiency. Roodman (2009b) notes that the problems arising from instrument proliferation are most severe in the case of system GMM. Judson and Owen (1999) show in Monte Carlo simulations that when $T$ becomes large the one-step GMM estimator outperforms the two-step. We therefore use the one-step variant of difference GMM in our estimations.

We use tests for over-identification and the tests for first and second order serial correlations to choose our preferred specification and the set of instruments. The first is the Sargan test for over-identification (Sargan 1958), which requires non-rejection of the null hypothesis that the instruments are valid. The Sargan test is robust to instrument proliferation but not to heteroscedasticity. We also use the Hansen test (Hansen 1982) that, like the Sargan test, requires non-rejection of the null hypothesis that the instruments are valid. The Hansen test, however, is robust to heteroscedasticity, but not to instrument proliferation. A large number of instruments can severely weaken the Hansen test pro- 
ducing questionably high $p$-values. We also use serial correlation tests (Arellano and Bond 1991). White noise errors $\varepsilon_{i t}$ would imply a MA(1) process for the $\Delta \varepsilon_{i t}$, thus the specification test is passed by rejecting the null of no first order serial correlation but not rejecting the null of no second order serial correlation. We also check the robustness of our results to reductions of the lags used in the instrument set and, as discussed below, to sample selection.

We estimate equation (3) via Pooled OLS, Within Group (WG), and GMM and present the results in Table 2. (We do not report estimated coefficients of dummy variables for missing or zero fundraising, administrative expenditure, government grant, autonomous income or price variables). Cluster robust standard errors are reported in parentheses (the charities are the clusters). We first estimate a fully dynamic model including lags on all regressors using GMM (results not reported). None of the lagged regressors, with the exception of lagged donations, are significant at the 10 per cent level and they are jointly insignificant ( $p$-value $=0.862$ ). We therefore take as our starting point a partial adjustment specification. We also estimate the model (not reported) with two lags and the results are qualitatively the same with the two-period lags insignificant for all regressors.

\section{[Table 2 about here]}

Columns (1) to (5) report results from the partial adjustment models. Column (1) presents the results from a pooled OLS estimation of equation (1). There is no allowance made for unobserved charity-specific effects or for the endogeneity of the charity-specific regressors. We test for the presence of fixed individual effects and, using an $F$-test, reject the null of no individual effects ( $p$-value $=0.000$ ) indicating the pooled OLS estimator is inconsistent. ${ }^{14}$ Column (2) presents results from the WG estimation (i.e. OLS on variables entered in deviations from time-means) which allows for unobserved charityspecific effects but not for the endogeneity of the charity-specific regressors. Column (3) presents results from GMM, allowing for fundraising, administrative expenditure, gov-

\footnotetext{
14 Orme and Yamagata (2006) show that inferences from the standard F-test procedure are still asymptotically valid when $N \rightarrow \infty$ and $T$ is fixed.
} 
ernment grants and autonomous income to be correlated with both the idiosyncratic error $\varepsilon_{i t}$ as well as the charity specific unobservable $\alpha_{i}$ and treating price as predetermined (uncorrelated with contemporaneous errors but correlated with past errors). The model in column (3) is estimated with all the lags (two lags and deeper) of the administrative expenditure, fundraising, grants and autonomous income (quadratically) as instruments. As price is pre-determined, its one period lag is also included as a valid instrument.

While the results of $\mathrm{AR}(1)$ and $\mathrm{AR}(2)$ tests are acceptable for all the GMM models, those from the Sargan and Hansen tests are not. In column (3) both tests have $p$-values close to 1, which, in the case of the Hansen test, is the result of the large instrument set. ${ }^{15}$ To reduce the number of instruments used in estimation, we truncate the lags to be included in the construction of the instrument set. The estimated coefficients display substantial robustness to the choice of instrument set (see Table C.1 in Appendix C) although the model performs the best with respect to the specification tests discussed when the lag length of the instrument set is truncated at 5 (column (4) of Table 2). Alternative specifications (fully logarithmic and log-linear) of equation (3) were also estimated but were rejected by the data, failing the Sargan and/or Hansen tests for all lag depths.

The quadratic terms for the charity specific variable other than fundraising in column (4) are jointly insignificant ( $p$-value $=0.530$ ). We therefore also report results from a more parsimonious specification where only fundraising enters quadratically to verify that the model is not over-parametrised thus masking the effects of the charity specific regressors. These effects remain insignificant though the partially quadratic specification model in column (5) performs better on the specification tests. Here the model performs best with the lag depth truncated at seven.

The significance of lagged donations in the model indicates that a static specification is mis-specified and may be subject to omitted variable bias. We estimate a static version of equation (3) via GMM and find that the Sargan test is not passed, for any lag depth of the instrument set, which can indicate model mis-specification (Cameron and Trivedi

\footnotetext{
${ }^{15}$ In general, a $p$-value close to 1 signifies a problem with the test-statistic's distribution under the null.
} 
2005). This is further evidence in favour of our dynamic specification. The size of the coefficient on the lagged dependent variable falls by about a third between the OLS and GMM estimations in columns (1) and (3). The estimated coefficients in columns (2) and (3) are generally very similar in size and significance though the similarities between the WG and GMM estimates are reduced when the instrument set is truncated and specification tests passed, suggesting that failure to reduce the number of instruments may indeed result in the GMM estimator failing to 'expunge the endogenous components'. The price of donating is not significant in any of the models that pass the required specification tests.

As the GMM estimator used in column (5) passes the four specification tests of interest, we take this to be our base model. The results from this partially quadratic specification are also very robust to the choice of instrument set lag depth (see Table C.2 in Appendix C). We also check the results for robustness to sample selection in Table 3 as there is the possibility that the construction of our dataset leads to an endogenously generated sample. As discussed in Section 3, whether a particular charity appears in the dataset for a particular year depends on whether the charity was ranked among the top $R$ in terms of the amount of donations received by this charity in that year. The data collection procedure saw the value of $R$ increase from 200 in 1978 to 500 in 1991 . In the absence of suitable instruments to deal with endogenous selection that might not be adequately captured by the lags of the regressors, we check for sensitivity of the results to different choices made with regard to the sample selected for the estimation.

\section{[Table 3 about here]}

We re-estimate equation (3) via GMM using only the single longest run of data (median of six years) for each charity (column (1)), only those charities with at least 6 observations, only those charities which appear in the data prior to 1985 (column (3)), only those charities which appear in the data prior to 1991 (column (4)) and replacing the macroeconomic variables with a time trend (column (5)). We find general stability in the size and significance of the coefficients. The coefficients in columns (1) to (5) are very 
similar to those in column (5) of Table 2, our base model. The estimated coefficient on the lagged dependent variable is smallest when using only the single longest spell for each charity, which given the prevalence of gaps in our panel, excludes about a third of our observations. Note that the price remains insignificant at conventional levels regardless of the sample used.

\section{Discussion}

Our discussion focuses on the results from our base model of giving for development, column (5) in Table 2. Our dynamic specification means that both short- and long-run effects can be identified. The estimated coefficients on the Group A and B regressors can be interpreted as the short-run effects. The long-run effects are obtained by dividing these coefficients by one minus the estimated coefficient on lagged donations (We have noted that the data reject the conventionally used static specification where the short and long run effects are assumed to be the same.) The size and significance of lagged donations is robust to both sample selection (see Table 3) and the choice of instrument set (see Appendix C). We discus the short- and long-run effects of each variable in detail below.

\section{Macroeconomic variables (Group A)}

We do not find evidence that ODA crowds out private donations - the coefficient on the $\log$ (net) ODA is statistically insignificant. This result is robust to the sample used in the estimation. We also estimated the model using alternative specifications of ODA (levels, share of GDP) but results were consistently insignificant. We cannot reject the hypothesis that changes in the public provision of the public good, ODA, have no effect on private giving, ceteris paribus.

Household income has a reasonably well-defined short-run impact, statistically significant at the 2 per cent level. The estimated elasticity of 0.63 indicates giving to be a necessity in the short run but we cannot reject the hypothesis of a unitary elasticity ( $p$ value $=0.341$ ). This suggests that overseas donations are not very sensitive to changes in 
income in the short run, contrary to the worst fears of how donations respond in recessionary periods. The estimate is generally robust to the selected sample, differing only for the pre-1985 sample (see Table 3, Column 3). The point estimate of the long-run income elasticity of development donations is substantially higher than that of the short-run effect, 1.81 ( $\mathrm{se}=0.59)$, but again a null hypothesis of a unitary elasticity cannot be rejected. ${ }^{16}$

The impact of changes in the distribution of income, measured by the ninety-fifty ratio, is not statistically significant although it is somewhat sensitive to sample selection (see Table 3). We test the sensitivity of this result to the choice of distributional metric by re-estimating the model using a Gini coefficient. Results are not qualitatively affected as the sign and significance of changes in the distribution of income is the same regardless of the choice of distributional metric.

We find some evidence of a significant negative effect as the significance of the coefficient on the ninety-fifty ratio displays some sensitivity to sample selection. This result conflicts with the prediction of Glazer and Konrad (1996), though their model has no development-specific component. The result suggests that greater inequality will decrease giving for international development. This may be due to donors, observing increasing inequality and, thus, increasing relative need domestically, substituting towards domestic charities. Alternatively, it may be the case that wealthier are less generous though more work is needed in this area.

Both the Ethiopian famine and the Boxing Day Tsunami had a powerful, positive impact on giving for development. The Ethiopian famine saw donations to the development charities included in our panel increase on average by around a third in 1984. The insignificance of the 1985 dummy suggests that the continuation of the famine did not have an analogous impact in 1985. In fact, several large overseas charities, e.g. Oxfam, saw donations fall from 1984 to 1985, presumably as donations were diverted to the Band Aid Trust, which we exclude from our panel for a reason given earlier. Total giving for development, including to Band Aid, actually increased by around a fifth from 1984 to 1985.

\footnotetext{
${ }^{16}$ Standard errors for the long-run elasticities are obtained using the delta method (see Wooldridge 2002, p.44).
} 
The estimated impact of the 2004 tsunami is slightly smaller than that for the Ethiopian famine, donations rising on average by about 20 per cent.

We explore the possibility that the impact of the Ethiopian famine persisted by adding a time trend starting in 1986. (We cannot do this for Boxing Day Tsunami since it occurred at the end of the panel.) However, as not all development charities would have been affected by the famine (some played no part in the relief effort) we define the trend only for those charities that saw a large increase in donations. We define 'large' as an increase in donations of at least 20 per cent in 1984 and/or 1985, although we test the sensitivity of results to other definitions (defining 'large' as an increase of 10 per cent or 30 per cent makes little difference). We first estimated the model with a standard time trend taking a value of one in 1986 and increasing linearly. This is found to be statistically insignificant. We therefore introduce the possibility of a decaying long-run impact by replacing the time trend with its inverse (so the inverse trend is equal to one in 1986, 0.5 in 1987, 0.33 in 1988 and so on) and re-estimating the models in Table 2. Results for the impact of the famine are reported in Table 4. Coefficients on the other covariates were not materially affected.

\section{[Table 4 about here]}

The famine appears to have had a persistent effect on giving to those development charities that saw large increases in donations in 1984-85. Focusing on the results in column (5) of Table 4, we see that in 1986, donations to those charities were on average 21 per cent higher, ceteris paribus. The decaying effect, as we have modeled it, suggests that the persistent effect of the famine fell quickly, being inside a standard error by 1988-89.

\section{Charity level variables (Group B)}

The following discussion continues to focus on the results in column (5) of Table 2.

The impact of price, found to be large in absolute value and significant for UK development charities by Khanna and Sandler (2000), is not statistically significant in any of the models that pass the specification tests. To check the robustness of this result, various 
specifications of the model were estimated: for example, price is insignificant at the 10 per cent level when entered in logs.

The significance of price in previous studies may be due to using a variable based on current year values for its components, or a failure to properly account for endogeneity of donations and fundraising. The construction of the price variable using contemporaneous fundraising and administrative expenditure may result in it measuring some otherwise unmodelled non-linearity in fundraising. To test this, we estimated a model using a price variable constructed from contemporaneous fundraising and administrative expenditures. Treating price as endogenous now, we find that the impact of price becomes larger (-5.29) and significant, although only at the 10 per cent level $(p=0.067)$. However, inclusion of price in this way violates the observation rule used in the literature (Tinkelman 2004).

The direct short-run impact of fundraising is well determined with a strong positive effect across almost all the observed range of expenditures. The turning point is near the very top of the distribution. ${ }^{17}$ The first negative impact of additional fundraising, captured by the price variable, is found to be insignificant. The second, a 'reputation' effect, is described in the concavity of donations in fundraising with the very highest levels of expenditure reducing donations, consistent with donors perceiving such expenditure as profligate.

Estimates of fundraising effectiveness have been used in the past to identify the strategy of charitable fundraisers. A marginal effect not different from zero indicates that the charity is a gross revenue maximiser, fundraising until the marginal pound brings in no additional donations. If the marginal effect of fundraising is not different from one, then the charity is said to be a net revenue maximiser, fundraising until the marginal pound brings in one additional pound in donations. Results in earlier papers have suggested that development charities were net revenue maximisers (Khanna et al 1995) or fundraise short of net revenue maximisation in the long run (Khanna and Sandler 2000). Weisbrod and Dominguez (1986) found US charities to be gross revenue maximisers.

\footnotetext{
17 The quadratic function of fundraising is maximised when fundraising equals $£ 1.5$ million. There are 23 charity-year observations for development charities with fundraising that exceeds this level.
} 
At the mean value of fundraising, the short-run marginal effect of fundraising indicates that a $£ 1$ increase in fundraising will lead on average to a $£ 0.82$ increase in donations. This point estimate is consistent with development charities using a mixed strategy of net and gross revenue maximisation in the short-run. However, the standard error of the estimate (£0.33) means we cannot reject the hypothesis that the short-run marginal effect is equal to 1 , implying net revenue maximisation. The long-run marginal effect of fundraising is much higher, 2.14 with a standard error of 0.83 . This is comparable to the marginal effect for development charities estimated with static models by Khanna et al (1995) of 2.31 and by Khanna and Sandler (2000) of 2.44 and is consistent with development charities fundraising short of net revenue maximisation in the long run.

As price is consistently found to be statistically insignificant, we do not calculate the total fundraising effect, taking into account the negative impact of fundraising operating through the price, as is done in much of the earlier literature.

In addition to the potential crowding in/out of donations through changes in the provision of the public good in the form of ODA, changes in direct government funding to charities via grants may also crowd in/out donations as earlier authors have emphasised. We find no evidence of this for development charities. This result is robust to both sample selection and the choice of instrument set. Note that in the results in columns (2) and (3) of Table 2, where the endogeneity of grants is not instrumented (column (2)) or not expunged (column (3)), the coefficient on grants is positive and weakly significant indicating crowding in. That this effect disappears when appropriate instrumentation is employed further underlines the importance of accounting for endogenous relationships in models of donations.

A similar pattern can be seen for administrative expenditure as their estimated effect is positive and significant in the models that fail to properly deal with the endogeneity - see again columns (2) and (3) in Table 2. In the preferred model, column (5), administrative expenditure is found to have no ceteris paribus impact on donations, a result that is robust to sample selection and the choice of instrument set. The results for autonomous income are analogous. 


\section{The distributions of marginal effects}

Estimating marginal effects or elasticities at the mean characteristics assumes that charity fundraising strategies do not vary across charities. This assumption is shown to be violated in Tinkelman (2004), who noted that extreme values of expenditure can disproportionately affect elasticities calculated at mean characteristics. He found that the distribution of fundraising effects can be quite wide and that elasticities calculated at the mean characteristics were generally not similar in size or significance (even in sign) to the mean elasticity. Table 5 shows the distribution across charity-years of both our shortand long-run marginal effects of fundraising (under the assumption that the estimated parameters of the model are constant over charities and time).

\section{[Table 5 about here]}

The short-run effect calculated at the mean value of fundraising is about over 80 per cent larger than the mean marginal effect. The median marginal effect may provide a better summary statistic given the clear positive skew in the distribution of fundraising expenditure. On this basis, the 'average' development charity is closer to being a gross revenue maximiser than a net revenue maximiser in the short run. In the long run it is less clear that the 'average' charity fundraises short of net revenue maximisation. There is substantial variation not only between different charities but also within charities over time. Given this situation, drawing conclusions about objective functions of charity fundraisers must be done with care. The fundraising objective may vary not only from one charity to another (see the between group standard deviations), but also over time for the same charity (see the within group standard deviations). Note that we also report the distribution of the fundraising elasticities, though the pattern will be the same as these elasticities are simply a monotonic transformation of the marginal effects.

Having obtained the marginal effects for each charity-year, we can relate them to both the level of fundraising expenditure and time. We regress the long-run marginal fundraising effects on the lag of fundraising expenditure and a time trend using a within group 
estimator (the unit of analysis is the charity-year). Results were essentially identical when contemporaneous fundraising expenditure was used. The coefficient on fundraising expenditure is negative by definition given the concavity of donations in fundraising. The coefficient on the time trend is equal to 0.06 (se=0.017). ${ }^{18}$ Results suggest that for development charities, the marginal pound spent on fundraising brought in on average $6 \mathrm{p}$ more than the previous year. per year. This means that over time development charities have moved away from revenue maximisation towards a strategy of net revenue maximisation. Such a change might occur if the objective function of charities has in fact changed. At one time managers of charities may have seen their role as maximising the revenue of their organisation. Over time managers may have shifted their priorities to net revenue or programme expenditure maximisation, no longer willing to reduce programme expenditure by 1 in order to generate a marginal increase in donations of $1 \mathrm{p}$.

If the objective function of charities has not changed, this increase in the marginal return to fundraising may also be in part driven by the research in this field, which has generally found a significant price effect. We have shown here that, in the case of development charities, a reasonable observation rule for the price and appropriate estimation procedures that expunge the endogenous components of price, result in the price being statistically insignificant. Charity managers operating under the assumption that fundraising expenditure will have a negative impact on donations via the price will underestimate the revenue maximising level of fundraising.

\section{Conclusions}

In this paper we have modelled the determinants of donations received by overseas development charities in the $\mathrm{UK}$, contributing to the relatively small literature on charitable giving that considers particular causes. We have used panel data that span over 25 years, and have drawn both on recent theory on giving for overseas causes and on advances in recent years in the econometrics of panel data. Our results may be summarised as follows:

\footnotetext{
${ }^{18}$ Using cluster robust standard errors
} 
- A dynamic specification is a useful advance on the static models previously used in the literature. Our charity panel easily rejects a static model. As a result we are able to identify both short-run and long-run impacts of regressors.

- We find no evidence that public provision of the public good in the form of ODA has crowded out donations for development, a possibility that had not been considered in the extensive existing literature on crowding out. Nor do we find evidence either of crowding out or of crowding in by government grants to development charities.

- We cannot reject the hypothesis that giving to overseas development has a unitary income elasticity in both the short and long run. This is in line with results from survey microdata on individuals and their giving (Micklewright and Schnepf 2009). Inter alia, a unitary elasticity implies that recessions do not have devastating impacts on charitable giving. We find no robust significant impact from changes in the inequality of household incomes, holding constant total income though there is some weak evidence suggesting that increased inequality decreases giving for development.

- Fundraising has a powerful effect on donations received by development charities but the effect appears not to be monotonic. We find that the impact of the price faced by donors, as conventionally defined in the literature, is not a significant determinant of donations.

- Estimating marginal effects and elasticities at the mean characteristics can produce results which are not representative of the average charity. When effects are calculated for each charity-year we find that the mean effect is not the same as the effect calculated at the mean characteristic. When considering the distribution of marginal effects, the 'average' development charity fundraises more closely to net revenue maximisation than when considering the marginal effect calculated at the mean characteristics. Moreover, there is evidence that the marginal effect of fundraising for development charities has increased over time. This may indicate a change in the 
objective function of charities or of the underestimation of the revenue maximising level of fundraising expenditure.

- There is some evidence to suggest that the marginal effect of fundraising has increased over time. This may indicate a shift in the objective function of development charity managers away from gross revenue maximisation. 


\section{References}

Alfaro, R., Apr. 2008. Estimation of a dynamic panel data: The case of corporate investment in chile. Tech. rep., Central Bank of Chile.

Alvarez, J., Arellano, M., 2003. The time series and Cross-Section asymptotics of dynamic panel data estimators. Econometrica 71 (4), 1121-1159.

Andreoni, J., 2006. Philanthropy. In: Kolm, S. C., Ythier, J. M. (Eds.), Handbook of the Economics of Giving, Altruism and Reciprocity. No. 2. Amsterdam, North Holland.

Andreoni, J., Payne, A. A., 2003. Do government grants to private charities crowd out giving or fund-raising? American Economic Review 93 (3), 792-812.

Arellano, M., Bond, S., 1991. Some tests of specification for panel data: Monte carlo evidence and an application to employment equations. Review of Economic Studies 58 (2), 277-97.

Atkinson, A., Jun. 2009. Giving overseas and public policy. Journal of Public Economics 93 (5-6), 647-653.

Atkinson, A. B., Backus, P. G., Micklewright, J., Pharoah, C., Schnepf, S. V., 2008. Charitable giving for overseas development: UK trends over a quarter century. IZA Discussion Paper 3872, forthcoming Journal of the Royal Statistical Society, Series A.

Atkinson, R., Eastwood, A., Sep. 2007. Public attitudes to overseas giving: Does government make a difference? S3RI Applications \& Policy Working Papers, A07/05.

Bover, O., Arellano, M., 1995. Female labour force participation in the 1980s the case of spain. Investigaciones Economicas 19 (2), 171-194.

Cameron, A. C., Trivedi, P. K., May 2005. Microeconometrics: methods and applications. Cambridge University Press.

Duncan, B., May 1999. Modeling charitable contributions of time and money. Journal of Public Economics 72 (2), 213-242.

Feldstein, M., 1975. The income tax and charitable contributions part II: the impact on religious, educational and other organizations. National Tax Journal 28 (2).

Glazer, A., Konrad, K. A., 1996. A signaling explanation for charity. American Economic Review 86 (4), 1019-28.

Hansen, L. P., 1982. Large sample properties of generalized method of moments estimators. Econometrica 50 (4), 1029-1054.

Horne, C. S., 2005. Do charitable donors know enough-and care Enough-About government subsidies to affect private giving to nonprofit organizations? Nonprofit and Voluntary Sector Quarterly 34 (1), 136-149.

House of Commons, 2009. Aid under pressure: Support for development assistance in a global economic downturn. 
Judson, R. A., Owen, A. L., Oct. 1999. Estimating dynamic panel data models: a guide for macroeconomists. Economics Letters 65 (1), 9-15.

Khanna, J., Posnett, J., Sandler, T., 1995. Charity donations in the UK: new evidence based on panel data. Journal of Public Economics 56 (2), 257-272.

Khanna, J., Sandler, T., 2000. Partners in giving:: The crowding-in effects of UK government grants. European Economic Review 44 (8), 1543-1556.

Micklewright, J., Schnepf, S. V., 2009. Who gives charitable donations for overseas development? Journal of Social Policy 38 (2), 317-341.

Nickell, S., Nov. 1981. Biases in dynamic models with fixed effects. Econometrica 49 (6), $1417-1426$.

Okten, C., Weisbrod, B. A., Feb. 2000. Determinants of donations in private nonprofit markets. Journal of Public Economics 75 (2), 255-272.

Orme, C., Yamagata, Y., 2006. The asymptotic distribution of the F-Test statistic for individual effects. Econometrics Journal 9, 404-422.

Peloza, J., Steel, P., 2005. The price elasticities of charitable contributions: A MetaAnalysis. Journal of Public Policy and Marketing 24 (2), 260-272.

Posnett, J., Sandler, T., 1989. Demand for charity donations in private non-profit markets : The case of the U.K. Journal of Public Economics 40 (2), 187-200.

Roodman, D., 2009a. How to do xtabond2: An introduction to difference and system GMM in stata. Stata Journal 9 (1), 86-136.

Roodman, D., 2009b. A note on the theme of too many instruments. Oxford Bulletin of Economics and Statistics 71 (1), 135-158.

Rose-Ackerman, S., 1982. Charitable giving and "Excessive" fundraising. The Quarterly Journal of Economics 97 (2), 193-212.

Sargan, J. D., 1958. The estimation of economic relationships using instrumental variables. Econometrica 26 (3), 393-415.

Solimano, A., 2005. Remittances by emigrants: issues and evidence. In: Atkinson, A. B. (Ed.), New Sources of Development Finance. Oxford University Press.

Tinkelman, D., Aug. 2004. Using nonprofit organization-level financial data to infer managers' fund-raising strategies. Journal of Public Economics 88 (9-10), 2181-2192.

Weisbrod, B. A., Dominguez, N. D., Jun. 1986. Demand for collective goods in private nonprofit markets: Can fundraising expenditures help overcome free-rider behavior? Journal of Public Economics 30 (1), 83-96.

Wooldridge, J. M., 2002. Econometric analysis of cross section and panel data. The MIT press, Cambridge, Mass. 


\section{Appendix A. The charities used in this study}

Table A.1: The charities used in this study

\begin{tabular}{|c|c|c|c|}
\hline (1) & (2) & (3) & (4) \\
\hline 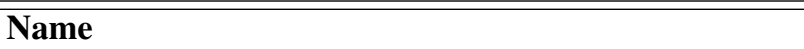 & First Year & 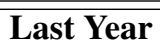 & 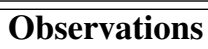 \\
\hline Acord & 1992 & 2003 & 7 \\
\hline Actionaid & 1977 & 2004 & 25 \\
\hline Africa Now & 1987 & 1990 & 4 \\
\hline Amnesty International UK Section Charitable Trust & 1992 & 2004 & 12 \\
\hline Befrienders International & 1995 & 1999 & 4 \\
\hline Book Aid International & 1993 & 2004 & 11 \\
\hline Britain-Nepal Medical Trust & 1986 & 1992 & 4 \\
\hline British Leprosy Relief Association (Lepra) & 1977 & 2004 & 25 \\
\hline British Red Cross Society & 1977 & 2004 & 25 \\
\hline Care International UK & 1985 & 2004 & 17 \\
\hline Catholic Agency For Overseas Development & 1979 & 2004 & 25 \\
\hline Catholic Institute for International Relations & 1989 & 2004 & 11 \\
\hline Childrens Aid Direct & 1995 & 2000 & 5 \\
\hline Christian Aid & 1977 & 2004 & 26 \\
\hline Christian Children's Fund of Great Britain & 1985 & 1999 & 13 \\
\hline Co-workers of Mother Teresa & 1977 & 1993 & 15 \\
\hline Everychild & 1990 & 2004 & 13 \\
\hline Farm Africa & 1989 & 1996 & 4 \\
\hline Federation of Jewish Relief Organisations & 1980 & 2000 & 12 \\
\hline Impact Foundation & 1994 & 2001 & 7 \\
\hline Intermediate Technology Development Group & 1984 & 2004 & 20 \\
\hline International Boys Town Trust & 1986 & 1989 & 4 \\
\hline International Christian Relief & 1984 & 2001 & 16 \\
\hline Karuna Trust & 1987 & 2001 & 11 \\
\hline Leprosy Mission (International) & 1978 & 2001 & 21 \\
\hline Marie Stopes International & 1987 & 2004 & 17 \\
\hline Medecins Sans Frontieres (UK) & 1996 & 2004 & 7 \\
\hline Medical Aid for Palestinians & 1989 & 1996 & 6 \\
\hline Medical Aid For Poland Fund & 1982 & 1991 & 9 \\
\hline Medical Emergency Relief International Charitable Trust & 1997 & 2001 & 4 \\
\hline
\end{tabular}

Notes: This table presents, in alphabetical order, the names of the charities used in this study, the year each enters and exits our data and the number of observations we have for each. 
Table A.1: The charities used in this study (con't)

\begin{tabular}{llll}
$(1)$ & $(2)$ & $(3)$ & $(4)$ \\
\hline \hline Name & First Year & Last Year & Observations \\
\hline Medical Foundation for the Care of Victims & 1991 & 2004 & 13 \\
Methodist Relief And Development Fund & 1980 & 2001 & 17 \\
Mines Advisory Group & 1993 & 2003 & 6 \\
Oasis Charitable Trust & 1995 & 2004 & 8 \\
Ockenden Venture & 1981 & 2003 & 9 \\
\hline Operation Raleigh & 1985 & 2004 & 14 \\
Opportunity Trust & 1994 & 2000 & 4 \\
Oxfam & 1977 & 2004 & 26 \\
Plan International (UK) & 1984 & 2003 & 18 \\
Project Hope United Kingdom & 1996 & 2001 & 6 \\
\hline Quaker Peace and Service & 1981 & 2003 & 22 \\
Rokpa Trust & 1994 & 2000 & 6 \\
Save the Children Fund & 1977 & 2004 & 26 \\
Scottish Catholic International Aid Fund & 1986 & 2004 & 18 \\
Sightsavers & 1977 & 2004 & 25 \\
\hline SOS Children's Villages UK & 1986 & 2001 & 13 \\
SOS Sahel International & 1991 & 1999 & 5 \\
St Francis Leprosy Guild & 1977 & 1995 & 10 \\
St Josephs Hospice Association & 1986 & 2001 & 15 \\
Sudan United Mission & 1977 & 1984 & 7 \\
\hline Survive Miva & 1987 & 2001 & 11 \\
Tearfund & 1977 & 2004 & 26 \\
UNICEF & 1981 & 2004 & 22 \\
Voluntary Service Overseas & 1977 & 2004 & 26 \\
War On Want & 1978 & 2000 & 15 \\
\hline Wateraid & 1985 & 2004 & 19 \\
World Evangelism Society of Great Britain & 1985 & 1993 & 5 \\
World Vision UK & 1984 & 2004 & 20 \\
\hline \hline
\end{tabular}

Notes: This table presents, in alphabetical order, the names of the charities used in this study, the year each enters and exits our data and the number of observations we have for each. 


\section{Appendix B. Instrument proliferation and collapsing the instrument set}

To illustrate this problem, consider the following example with one endogenous regressor $x_{i t}$.

$$
y_{i t}=\beta x_{i t}+\alpha_{i}+\varepsilon_{i t} t=1, \ldots, 5
$$

If we were to apply 2SLS to estimate (3) in first-differences, $x_{i t-2}$ and higher order lags of $x$ can be used as an instrument for $\Delta x_{i t}$ under the assumption that $E\left[x_{i t}-s \Delta \varepsilon_{i t}\right]=$ 0 for $s \geq 2$. This would imply that the estimation sample would be $t=3, \ldots, 5$ and every additional lag of a variable to the set of instruments would result in the loss of one extra time observation. In contrast, the standard GMM-diff approach includes separate instruments for each time period resulting in a sparse instrument set but larger estimation sample. In the case of GMM-diff, the instrument matrix for charity i would be:

$$
Z_{i}=\left[\begin{array}{ccccccc}
x_{i 1} & 0 & 0 & 0 & 0 & 0 & 0 \\
0 & x_{i 1} & x_{i 2} & 0 & 0 & 0 & 0 \\
0 & 0 & 0 & x_{i 1} & x_{i 2} & x_{i 3} & 0 \\
. & . & . & . & . & . & . \\
. & . & . & . & . & . & .
\end{array}\right]
$$

For example, the instruments for the regressor's observation $\left(x_{i 3}-x_{i 2}\right)$ would be $x_{i 1}$. Three practical problems can result with the use of a sparse instrument set (Roodman 2009a). First, the instrument set can be too weak to identify the relevant effects. Second, the precision of the weighting matrix that is used in the GMM estimation is affected. Third, some of the statistical tests that are used for model validation can have low power. Given these problems, we investigated the approach of a strand of the literature where the standard GMM-diff instruments are combined through addition to create a smaller instrument set (Roodman 2009a). Taking the example discussed above, the new instrument matrix would be 


$$
Z_{i}=\left[\begin{array}{cccc}
x_{i 1} & 0 & 0 & . \\
x_{i 2} & x_{i 1} & 0 & \cdot \\
x_{i 3} & x_{i 2} & x_{i 1} & \cdot \\
\cdot & \cdot & \cdot & \cdot
\end{array}\right]
$$

This is using the 'collapse' option in estimation command xtabond2. 


\section{Appendix C. Variation in the depth of the instrument set}

Taking the model in column (3) of table 2, we wish to test the sensitivity of the results to truncation of the number of lags used in the instrument set. I present results from re-estimation of the using various truncations of the instrument set in table C.1.

Table C.1: Varying instrument set lag depth for partially quadratic model

\begin{tabular}{|c|c|c|c|c|c|c|}
\hline & (1) & (2) & (3) & (4) & (5) & (6) \\
\hline Estimator: & GMM & "GMM & 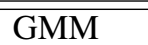 & GMM & $\overline{\text { GMM }}$ & $\overline{\text { GMM }}$ \\
\hline Lag depth: & $<3$ & $<4$ & $<5$ & $<6$ & $<11$ & $<16$ \\
\hline Lag Log Donations & $\begin{array}{l}0.735 * * * \\
(0.105)\end{array}$ & $\begin{array}{l}0.654 * * * \\
(0.110)\end{array}$ & $\begin{array}{l}0.698 * * * \\
(0.086)\end{array}$ & $\begin{array}{l}0.658 * * * \\
(0.085)\end{array}$ & $\begin{array}{l}0.641 * * * \\
(0.061)\end{array}$ & $\begin{array}{l}0.620 * * * * \\
(0.057)\end{array}$ \\
\hline
\end{tabular}

Group A: Macroeconomic Variables

\begin{tabular}{lllllll}
\hline Log HH Income & $0.610^{* *}$ & $0.699^{* *}$ & $0.618^{* *}$ & $0.657^{* *}$ & $0.591 * *$ & $0.648^{* * *}$ \\
& $(0.269)$ & $(0.272)$ & $(0.271)$ & $(0.276)$ & $(0.242)$ & $(0.238)$ \\
Log Net ODA & -0.062 & -0.019 & -0.042 & -0.042 & -0.015 & -0.002 \\
& $(0.146)$ & $(0.139)$ & $(0.129)$ & $(0.127)$ & $(0.108)$ & $(0.109)$ \\
90/50 ratio & -0.520 & -0.304 & -0.338 & -0.398 & -0.453 & -0.301 \\
& $(0.371)$ & $(0.366)$ & $(0.329)$ & $(0.320)$ & $(0.337)$ & $(0.322)$ \\
Tsunami & $0.217 * *$ & $0.218^{* *}$ & $0.220^{* *}$ & $0.203^{* *}$ & $0.189^{* *}$ & $0.206^{* *}$ \\
& $(0.098)$ & $(0.095)$ & $(0.095)$ & $(0.089)$ & $(0.084)$ & $(0.085)$ \\
1984 & $0.340^{* * *}$ & $0.351^{* * *}$ & $0.344^{* * *}$ & $0.337 * * *$ & $0.338^{* * *}$ & $0.348^{* * *}$ \\
& $(0.109)$ & $(0.108)$ & $(0.109)$ & $(0.108)$ & $(0.110)$ & $(0.109)$ \\
1985 & 0.027 & 0.030 & 0.021 & 0.031 & 0.036 & 0.036 \\
& $(0.075)$ & $(0.079)$ & $(0.076)$ & $(0.078)$ & $(0.077)$ & $(0.079)$
\end{tabular}

Group B: Charity Specific Variables

\begin{tabular}{lllllll}
\hline Price & -0.296 & -0.896 & -0.585 & -0.926 & -0.650 & $-1.112^{*}$ \\
Admin & $(0.876)$ & $(0.901)$ & $(0.791)$ & $(0.811)$ & $(0.685)$ & $(0.607)$ \\
& -0.277 & -0.201 & -0.190 & -0.029 & 0.034 & 0.000 \\
Fundraising & $(0.404)$ & $(0.398)$ & $(0.376)$ & $(0.299)$ & $(0.222)$ & $(0.206)$ \\
& 0.528 & 0.552 & 0.577 & $0.693^{* *}$ & $0.756^{* * *}$ & $0.729^{* * *}$ \\
Fundraising2 & $(0.423)$ & $(0.387)$ & $(0.356)$ & $(0.285)$ & $(0.236)$ & $(0.183)$ \\
& -0.178 & -0.182 & $-0.183^{*}$ & $-0.217^{* *}$ & $-0.256^{* * *}$ & $-0.236^{* * *}$ \\
Grants & $(0.131)$ & $(0.123)$ & $(0.108)$ & $(0.089)$ & $(0.072)$ & $(0.061)$ \\
& 0.048 & 0.075 & 0.054 & 0.020 & 0.010 & 0.032 \\
Autonomous Inc & $(0.065)$ & $(0.080)$ & $(0.050)$ & $(0.038)$ & $(0.037)$ & $(0.028)$ \\
& -0.034 & -0.054 & -0.045 & -0.025 & -0.003 & -0.031 \\
Charities & $(0.064)$ & $(0.071)$ & $(0.056)$ & $(0.047)$ & $(0.031)$ & $(0.024)$ \\
Observations & 58 & 58 & 58 & 58 & 58 & 58 \\
Instruments & 577 & 577 & 577 & 577 & 577 & 577 \\
AR(1) & 32 & 44 & 56 & 68 & 128 & 188 \\
AR(2) & 0.037 & 0.073 & 0.000 & 0.000 & 1.000 & 1.000 \\
Hansen & 0.146 & 0.113 & 0.121 & 0.120 & 0.168 & 0.125 \\
Sargan & 0.037 & 0.073 & 0.000 & 0.000 & 1.000 & 1.000 \\
\hline \hline
\end{tabular}


Taking the model in column (4) of table 2, we wish to test the sensitivity of the results to truncation of the number of lags used in the instrument set. Results are presented in table C.2. 
Table C.2: Varying instrument set lag depth for fully quadratic model

(1)

(2)

(3)

(4)

(5)

(6)

\begin{tabular}{lllllll}
\hline \hline $\begin{array}{l}\text { Estimator: } \\
\text { Lag depth: }\end{array}$ & $\begin{array}{l}\text { GMM } \\
<3\end{array}$ & $\begin{array}{l}\text { GMM } \\
<4\end{array}$ & $\begin{array}{l}\text { GMM } \\
<5\end{array}$ & $\begin{array}{l}\text { GMM } \\
<6\end{array}$ & $\begin{array}{l}\text { GMM } \\
<11\end{array}$ & $\begin{array}{l}\text { GMM } \\
<16\end{array}$ \\
\hline Lag Log Donations & $\begin{array}{l}0.707^{* * *} \\
(0.109)\end{array}$ & $\begin{array}{lllll}0.651^{* * *} \\
(0.100)\end{array}$ & $\begin{array}{l}0.655^{* * *} \\
(0.091)\end{array}$ & $\begin{array}{l}0.646^{* * *} \\
(0.090)\end{array}$ & $\begin{array}{l}0.615^{* * *} \\
(0.069)\end{array}$ & $\begin{array}{l}0.601^{* * *} \\
(0.068)\end{array}$
\end{tabular}

Group A: Macroeconomic Variables

\begin{tabular}{lllllll}
\hline Log HH Income & 0.479 & $0.575^{* *}$ & $0.508^{* *}$ & $0.538^{* *}$ & $0.567^{* *}$ & $0.639^{* * *}$ \\
& $(0.296)$ & $(0.259)$ & $(0.249)$ & $(0.251)$ & $(0.231)$ & $(0.231)$ \\
Log Net ODA & 0.017 & 0.038 & 0.036 & -0.008 & 0.034 & 0.052 \\
& $(0.144)$ & $(0.141)$ & $(0.136)$ & $(0.141)$ & $(0.117)$ & $(0.115)$ \\
$90 / 50$ ratio & -0.567 & -0.238 & -0.236 & -0.287 & -0.208 & -0.230 \\
& $(0.495)$ & $(0.449)$ & $(0.348)$ & $(0.362)$ & $(0.315)$ & $(0.301)$ \\
Tsunami & $0.241^{* *}$ & $0.239^{* *}$ & $0.247^{* * *}$ & $0.225^{* *}$ & $0.225^{* * *}$ & $0.233^{* * *}$ \\
& $(0.110)$ & $(0.103)$ & $(0.092)$ & $(0.089)$ & $(0.086)$ & $(0.084)$ \\
1984 & $0.327^{* * *}$ & $0.337^{* * *}$ & $0.331^{* * *}$ & $0.323^{* * *}$ & $0.343^{* * *}$ & $0.355^{* * *}$ \\
& $(0.109)$ & $(0.110)$ & $(0.109)$ & $(0.108)$ & $(0.109)$ & $(0.107)$ \\
1985 & 0.018 & 0.011 & 0.002 & 0.013 & 0.025 & 0.030 \\
& $(0.092)$ & $(0.092)$ & $(0.085)$ & $(0.086)$ & $(0.083)$ & $(0.083)$
\end{tabular}

Group B: Charity Specific Variables

\begin{tabular}{lllllll}
\hline Price & -13.010 & -13.620 & $-15.744 * *$ & -13.332 & -5.969 & -7.226 \\
& $(13.722)$ & $(11.819)$ & $(7.467)$ & $(8.164)$ & $(7.144)$ & $(5.413)$ \\
Price2 & 5.146 & 5.164 & $6.056^{* *}$ & 5.027 & 1.954 & 2.494 \\
& $(5.711)$ & $(4.847)$ & $(3.054)$ & $(3.316)$ & $(2.845)$ & $(2.174)$ \\
Admin & 1.140 & 0.667 & 0.833 & 0.396 & 0.655 & 0.683 \\
& $(0.962)$ & $(0.750)$ & $(0.610)$ & $(0.593)$ & $(0.489)$ & $(0.439)$ \\
Admin2 & -0.927 & -0.435 & -0.566 & -0.078 & $-0.977 * *$ & $-0.874 * *$ \\
& $(1.349)$ & $(1.087)$ & $(0.950)$ & $(0.747)$ & $(0.465)$ & $(0.379)$ \\
Fundraising & $0.875^{* *}$ & $0.777^{* *}$ & $0.974^{* * *}$ & $1.036^{* * *}$ & $0.848^{* * *}$ & $0.808^{* * *}$ \\
& $(0.389)$ & $(0.348)$ & $(0.319)$ & $(0.247)$ & $(0.226)$ & $(0.186)$ \\
Fundraising2 & $-0.284^{* *}$ & $-0.230^{*}$ & $-0.308^{* * *}$ & $-0.330^{* * *}$ & $-0.279^{* * *}$ & $-0.266^{* * *}$ \\
& $(0.141)$ & $(0.123)$ & $(0.111)$ & $(0.079)$ & $(0.077)$ & $(0.067)$ \\
Grants & -0.050 & 0.025 & 0.021 & -0.025 & 0.001 & 0.047 \\
& $(0.267)$ & $(0.214)$ & $(0.186)$ & $(0.151)$ & $(0.098)$ & $(0.075)$ \\
Grants2 & 0.003 & -0.004 & -0.003 & -0.001 & -0.002 & -0.003 \\
& $(0.026)$ & $(0.022)$ & $(0.018)$ & $(0.015)$ & $(0.007)$ & $(0.006)$ \\
Autonomous Inc & -0.045 & -0.107 & -0.113 & -0.071 & -0.051 & -0.070 \\
& $(0.216)$ & $(0.200)$ & $(0.148)$ & $(0.120)$ & $(0.064)$ & $(0.051)$ \\
Autonomous Inc2 & 0.003 & 0.006 & 0.007 & 0.005 & 0.004 & 0.003 \\
& $(0.013)$ & $(0.013)$ & $(0.010)$ & $(0.008)$ & $(0.004)$ & $(0.004)$ \\
\hline Charities & 58 & 58 & 58 & 58 & 58 & 58 \\
Observations & 577 & 577 & 577 & 577 & 577 & 577 \\
Instruments & 40 & 56 & 72 & 88 & 168 & 248 \\
AR(1) & 0 & 0 & 0 & 0 & 0 & 0 \\
AR(2) & 0.076 & 0.068 & 0.058 & 0.07 & 0.096 & 0.082 \\
Hansen & 0.119 & 0.000 & 0.032 & 0.872 & 1 & 1 \\
Sargan & 0.154 & 0.38 & 0.544 & 0.16 & 0.76 & 0.978 \\
\hline \hline
\end{tabular}

